\title{
ADULT VISITORS' INTELLECTUAL FUNCTIONING EXPLORING CONTEMPORARY ART: EXPERIENCES THAT GENERATE SELF-DISCOVERY ${ }^{1}$
}

\author{
Anne-Marie Émond \\ Département de didactique, Université de Montréal (Canada)
}

\begin{abstract}
Objectives: The aim of our research centres around accessing and understanding the intellectual functioning of adults' art experience encountering contemporary art in a museum context.

Methods: In order to access a visitor's aesthetic experience, the Thinking Aloud protocol (Dufresne-Tassé et al., 1998) was used to collect adult visitors' talk during their exploration of artworks at the Montreal Museum of Fine Arts. This method consists of recording what an individual visitor says, during his visit, that is, thoughts, ideas, reflections that might emerge during the exploration of artworks. The verbal comments of 67 visitors, aged 18 to 80 years old that possess different levels of education and frequent museums more than 3 times per year were recorded. The recorded comments were transcribed and analyzed using different instruments created in previous research projects (Emond, 2017).

Results: Our initial results are set in relation to Pelowski and Akiba's (2011) psychological model of art experience. Specifically, we present how visitors' contemporary art appreciation, that goes beyond the meta-cognitive stage, is the result of an art exploration that encourages imagining different selves and self-discovery (Minissale, 2013). Conclusion: This is to say that for a transformative aesthetic experience, an individual has to consider the pleasures of ambiguity featured by contemporary art. Our results reflect on the exploration of contemporary art as a form of creativity as proposed by Minnisale (2013), where visitors learn to valorize the process of adjusting their self-image through new experiences brought about by artworks.
\end{abstract}

Keywords: Adult visitors, intellectual functioning, art museum, contemporary art, aesthetic experience.

\section{Rationale of the research}

Psychological aesthetics research was often conducted in the context of a laboratory, one that is very different from an actual gallery space in a museum. Our previous research showed the importance of the artwork materiality, the museography and all the information provided by the museum on the quality of visitors' aesthetic experiences (Émond, 2016a,b) and in doing so, identifying the necessity to favour more research in such a context. In this study, we pursue our investigation on museum visitors aesthetic experience regarding contemporary art. More specifically, we are interested in documenting what actually happens to visitors during an encounter with contemporary art. We want to understand their art appreciation practices: what are their thoughts, how they deal with moments of harmony or conflict. By visitors' aesthetic responses, we refer to all the verbal comments made by visitors during their museum visit which gives us access to the different mental operations they might use to make sense of the artworks such as identifying, judging and predicting.

The purpose of the study is to identify the components of a transformative aesthetic experience in the context of a museum visit. How can a visitor, who experiences moments of conflict (dissonance) or of harmony (consonance), while viewing contemporary art in a museum, attain a transformative aesthetic experience?

\footnotetext{
${ }^{1}$ This research has been funded by the Social Sciences and Humanities Research Council of Canada (SSHRC).
} 


\section{The choice of participants}

Our 67 participants are frequent museum visitors, that is, they visit museums more than three times per year. They are all members of the Montreal Museum of Fine Arts where the research was conducted. Aged 18 to 80 years old they possess different levels of education ranging from less than twelve years of education to post-secondary education. It is important, in the context of our research, to have participants that are familiar with museums and feel at ease exploring works of art in order to maximize the potential of identifying the components of a transformative aesthetic experience.

\section{Procedure for collecting data}

In the 1990s, a number of researchers used the thinking aloud protocol to study problem resolution (Ericsson \& Simon, 1993; Winburg, 1991), text comprehension (Kukan \& Beck, 1997; Pressley \& Afflerbach, 1995), and decision-making (Rosman, Lubatkin, \& O’Neill, 1994). In 1995, Dufresne-Tassé and the Université de Montréal Groupe de recherche sur les musées et l'éducation des adultes - GRMEA (Research group for museums and adult education) adapted this method with a view to collecting adult visitors' comments in the instant where they take shape in the museum exhibition galleries, in order to study visitors' psychological functioning (Dufresne-Tassé \& Lefebvre, 1995). This method consists in recording what visitors say at the time of their visit. They don't have to make any effort to explain or justify their remarks, they are simply asked to express out loud what comes to their minds throughout their visit. They are invited to verbalize their experience as it unfolds.

As mentioned by Dufresne-Tassé and Lefebvre in their book Psychologie du visiteur de musée: contribution à l'éducation des adultes en milieu muséal [Psychology of museum visitors: a contribution to adult education in the museum context] (1995), there are conditions to be met in order to successfully obtain visitors' reactions during their exploration of artworks. Firstly, it is very important that individuals be willing to visit the museum. Secondly, they must be aware of the fact that they are going there to participate in research in which their role is essential. Thirdly, they must understand that they will be expressing their thoughts out loud throughout the visit. Consequently, the research situation created is one where individuals who accept to become visitor-participants wish to cooperate with the researcher and this encourages them to verbalize their thoughts as they come. The participants are unrestricted in their choice of contemporary artworks to be viewed in the permanent collection of international contemporary art at the Montreal Museum of Fine Arts in Quebec, Canada. During their museum visit, one visitor at a time, is being accompanied by the researcher who is attentive to the visitors' comments that are recorded for the purpose of the study. Depending on each visitor, the duration of the visit varies between one and three hours. The data collected during this time is later transcribed and consist of what we call a 'discourse'. This discourse is then used to analyse each visitor's aesthetic experience.

\section{Treatment of data}

Through a visitor's discourse, an analysis is made using instruments created in previous research. One consists of a typology of consonances and dissonances to identify moments of harmony and/or of conflict, and another, regroups eight mental operations that could be used by the visitor during the art exploration (see Émond, 2017 for details). Once all the discourses are coded, we are able to put visitors' consonant and dissonant moments and the different mental operations used in relation to Pelowski and Akiba's (2011) psychological model of art experience. This model presents five different stages of the aesthetic experience: Stage 1: Pre-expectations and self-image; Stage 2: Cognitive mastery and introduction of discrepancy; Stage 3: Secondary control and escape; Stage 4: Meta-cognitive re-assessment; Stage 5: Aesthetic outcome and new mastery, with a total of three possible Outcomes to the aesthetic experience.

\section{Results and discussion}

\subsection{Meta-cognitive re-assessment and aesthetic outcome and new mastery}

In Pelowski and Akiba's (2011) psychological model of art experience, as presented by Émond (2018), all stages have a particular role to play in the quality of visitors' museum experience. Nonetheless, it is important in the context of this study to concentrate our analyses on what we consider a crucial stage in the aesthetic experience of contemporary art, that is, Stage 4: Meta-cognitive re-assessment. As reported by Émond (2018): 
When a visitor finds himself prisoner in a situation where he has no way of escaping or easily resolving the dissonance, he/she is experiencing while being engaged with a contemporary work of art, he can decide to enter in "a period of active experiential and expectational re-assessment" (p. 89). If the visitor decides to continue with an experiential re-evaluation, "this event is often accompanied or preceded by acute self-focused attention" (Steele et al., 1993, as cited by Pelowski \& Akiba, 2011, p. 89), which seems to have an impact on dissonant situations (Pelowski \& Akiba, 2011). Becoming self-focused, "leads [the visitor] to the feeling of "increased submissiveness" and "individuation", causes the individual to "focus attention on personal limitations and to increase perceived uncontrollability" (Rothbaum et al., 1982, p. 23), increases negative affect and anxiety (Mor \& Winquis, 2002); and induces expectational re-assessment (Ingram, 1990)" (Pelowski \& Akiba, 2011, p. 89). The visitor, then gives up total control and revises his expectations acknowledging the presence of the dissonance or conflict and switches to a meta-cognitive approach in his art appreciation. The visitor who can reach this stage is gearing towards a transformative aesthetic experience. There is therefore a metacognitive re-assessment. If successful, the visitor will modify his self-image and achieve self-transformation (Rothbaum et al., 1982, as cited by Pelowski \& Akiba, 2011).

When the visitor completes Stage 4 and enters into Stage 5: aesthetic outcome and new mastery, he is getting closer to an Outcome 3, that is, a transformative aesthetic experience. To complete Stage 5, the visitor must change his pre-expectations and self-image. We could say that the visitor is receptive to new experiences.

Being in a creative pursuit, allows the visitor to explore his identity, forging new knowledge and self-insight. It is as if the contact with contemporary art, almost conceived to create dissonances on the part of the visitor, challenges the way he appreciates art and ferment change. As mentioned by Radford (2004) "[it] may be that some works of conceptual art are simply centered on challenging boundaries, at setting up dissonances" (p. 56). The role of cognitive dissonances is unavoidable in the exploration of contemporary art, it contains "[the] notion of tension and reconciliation, and of the creative act as speaking to something "within us" and revealing to us something about ourselves..." (Radford, 2004, p. 56).

The visitor that overcomes the challenges inherent to the exploration of contemporary artworks, seems to put into action his creativity. In these circumstances, the visitor appears to tolerate ambiguity and is willing to go beyond his comfort zone in his art appreciation. In doing so, the visitor withholds his aesthetic judgement and, as Gomez (2007) mentions, "enables an idea to survive long enough to generate other ideas" (p. 35) and prolonging the aesthetic experience. This type of aesthetic experience generates, on the part of the visitor a certain fascination with the unusual. When this occurs, we can find evidence of metacognitive knowledge, experiences and skills on the part of the visitor.

Identifying metacognitive knowledge in a visitor's discourse "refers to a person's conceptions of cognitive processes, such as thoughts about mental images, beliefs, and insights" (Gutwill \& Dancstep, 2017, p. 73). To illustrate this, the visitor could say "I'm a person that looks for beautiful works of art" (MBAM AA). As for, metacognitive experiences we find in a visitor's discourse "awareness of thoughts or feeling, such as frustration or excitement" (Gutwill \& Dancstep, 2017, p. 73). An example would be, "I am angry when I see found objects in an artwork" (MBAM AA). Finally, concerning metacognitive skills, a visitor might say "When I am not sure about the meaning of the artwork, I read the label to find out what is happening" (MBAM AA) as it involves "strategies aimed at monitoring cognition, such as orientation, planning and evaluation" (Gutwill \& Dancstep, 2017, p. 73).

Art becomes a vehicle to construct and understand the self (Brinck, 2007). This entails, on the part of a museum visitor, to create meaning from his exploration of an artwork, and this, through time. The exploration of an artwork becomes a work in progress where every encounter contributes to self-discovery.

When the visitor is capable of understanding the divergent or dissonant elements of his aesthetic experience and integrates them as new self-knowledge, this will influence his future art exploration. Kokkos (2010) refers to Mezirow (2000) in saying that:

[...] transformative learning occurs when there is a transformation in our set of specific beliefs, feelings and attitudes (points of view) or in our broader orienting predisposition (habit of mind). Transformation in a habit of mind may be sudden (epochal) or slower through incremental changes in various points of view. The entry point to a transformative process is the disorienting dilemma - a kind of learning disability felt by a person... (pp. 173-174). 
At this point, just has Minissale (2013) pointed out, contemporary art appreciation requires that a visitor takes pleasure being in a state of ambiguity. On the part of the visitor, it does not require definitive conclusion of his art appreciation, just the recognition of multiple possibilities of interpretations that reinforces the pleasure of ambiguity. As an example, our visitor MBAM BR said: "In the past, I passed right off the things I did not like... because I did not like it, it's not beautiful, it doesn't tell me anything. But now I'm going to spend a little more time looking..." This visitor is now capable of understanding the divergent or dissonant elements of his aesthetic experience and integrate this new self-knowledge for his future encounters with artworks and in doing so, modifies his preconceptions about artworks, thus his self-image.

When this happens, the museum visitor may experience a sense of "fitness" with the artwork and the artist. A sense of "true self" (Csikszentmihalyi, 1990) occurs and the visitor might lose track of time. At this point, we might find moments akin to flow experiences that entails, amongst others, the loss of self-consciousness. The museum visitor might experience a sense of enlightenment, epiphany and pleasure that calls for a repeat museum experience in the exploration of contemporary works of art.

\section{Conclusion}

Our results indicate that to help visitors achieve the transformative aesthetic experience, educators need to develop educational programs accompanied by mediation that would help visitors question their preconceptions about art and accompany them in their exploration of contemporary art, in a spirit of openness. As Minissale (2013) claims:

In this way, art can be seen as some kind of exchange between different selves, helping to structure self-knowledge....The experience of the work of art is akin to enjoying the exploration of the self as something unresolved, which may or may not dissipate when one has left the gallery space" (p. 5318, p. 5322).

Change occurred in our visitor MBAM AA while he was exploring contemporary artworks. What he experienced may have an incidence on his future museum visits. In his words:

I think that art must be beautiful. It must be fun. But it makes me fall into a trap of the artist in fact, I finally see...It's a revelation...I admit that...that's it, it's exactly what I had to experience looking at the work of art...because that was it. I will have learned a lot of things today, it's fascinating... But that's it, I feel assaulted...Oh, it's very funny. We do not give the artist enough credit. For us it's a reaction, then we do not go further...to say is that really what he wanted us to do? But then I realize...he does something like that to make us react. It makes sense, it's very funny.

Detailing the exact experiences that an artwork might provoke on a museum visitor is very difficult to accomplish, since it seems that there are as many ways to do so, as there are visitors. Although, let's not forget that the aesthetic experience involves elements that are shared by all human beings and can be identified. We can find both positive such as pleasure or negative emotions such as disgust and some self-consciousness emotions such as embarrassment and some cognitive emotions such as confusion while exploring artworks (Silvia, 2009). One thing that became evident for some of our participants, like MBAM AA, is that exploring contemporary artworks demands an active approach, one that asks for a co-creation of the work of art.

With these words, we must now continue to grasp the components and dynamics of an awareness of self, experienced by visitors during an aesthetic experience, to better informed our actions as museum educators.

\section{References}

Brinck, I. (2007). Situated cognition, dynamic systems, and art: on artistic creativity and aesthetic experience. Janus Head, 9(2), 407-431. Retrieved December 1, 2018, from: http://www.janushead.org/9-2/brinck.pdf

Csikszentmihalyi, M. (1990). Flow; the psychology of optimal experience. New York: Harper Perennial.

Dufresne-Tassé, C. \& Lefebvre, A. (1995). Psychologie du visiteur de musée : Contribution à l'éducation des adultes en milieu muséal. Montréal, QC : Éditions Hurtubise HMH.

Dufresne-Tassé, C. Sauvé, M., Weltzl-Fairchild, A., Banna, N., Lepage, Y. \& Dassa, C. (1998). Pour des expositions muséales plus éducatives, accéder à l'expérience du visiteur adulte. Développement d'une approche. Canadian Journal of Education/Revue canadienne de l'éducation, 23(3), 302-315. 
Ericsson, K. A., \& Simon, H. A. (1993). Protocol analysis. Cambridge, MA: MIT Press.

Émond, A.M. (2016a). La pertinence pour les musées de développer des outils de médiations écrites pour l'appréciation de l'art contemporain. In A. Savoie, A.M. Émond, F. Gagnon-Bourget \& P. Gosselin (Eds.), Actes du Colloque sur la recherche en enseignement des arts visuels (pp. 26-32). Montréal, QC : CRÉA.

Émond, A.M. (2016b). Connaître les opérations mentales utilisées par les étudiants à la formation des maîtres pour traiter les œuvres d'art contemporain. In M. Théberge \& F. Chaîné (Eds.), Réfléchir à la formation artistique (48-76). Québec, QC : Éditions FRÉA.

Émond, A.M. (2017). La voix des visiteurs en contexte muséal : matière première dans l'élaboration d'instruments permettant d'analyser et de cartographier le fonctionnement intellectuel d'adultes lors de leur traitement d'œuvres d'art contemporain. In C. Dufresne-Tassé \& A.M. Laraignée (Eds.), Numéro spécial sur la recherche, Volume 2 ICOM Éducation 27 (13-44). Retrieved from https://drive.google.com/file/d/1H4RsNSMKOtiqhGSz2rf9wVBF3CRAeC4W/view

Émond, A.M. (2018). The intellectual functioning of art museums' visitors: Identifying components of a transformative aesthetic experience. In C. Pracana \& M. Wang (Eds.), Psychological applications and trends 2018 (156-160). Retrieved from http://inpact-psychologyconference.org/wpcontent/uploads/2018/05/Psychological-Applications-and-Trends-2018.pdf

Gomez, J. G. (2007). What do we know about creativity? The Journal of Effective Teaching, 7(1), 31-43. Retrieved December 1, 2018, from https://pdfs.semanticscholar.org/3ad5/30c1138e10eb674e456c3ec4ed52cb0a209c.pdf

Gutwill, J.P. \& Dancstep, T. (2017). Boosting metacognition in science museums: Simple exhibit label designs to enhance learning. Visitor Studies, 20(1), 72-88.

Kokkos, A. (2010). Transformative learning through aesthetic experience: Towards a comprehensive method. Journal of Transformative Education, 8(3), 155-177. Retrieved December 1, 2018, from: https://pdfs.semanticscholar.org/5934/7b9e3b38154e84884162439feac8e2f21147.pdf

Kukan, L. \& Beck, I. L. (1997). Thinking aloud and reading comprehension research: Inquiry, instruction, and social interaction. Review of Educational Research, 67(3), 271-299.

Minissale, G. (2013). The psychology of contemporary art. New York, Cambridge University Press.

Pelowski, M., \& Akiba, F. (2011). A model of art perception, evaluation and emotion in transformative aesthetic experience. New Ideas Psychology. 29, 80-97. doi: 10.1016/j.newideapsych.2010.04.001

Pressley, M. \& Afflerbach, P. (1995). Verbal Protocols of reading: The nature of constructively responsive reading. Hillsdale, NJ: Lawrence Erlbaum.

Radford, M. (2004). Emotion and creativity. The Journal of Aesthetic Education, 38(1), 53-61. Retrieved December 1, 2018, from https://www.jstor.org/stable/3527362?seq=1\#metadata_info_tab_contents

Rossman, A., Lubatkin, M. \& O'Neill, H. (1994). Rigidity in decision behaviors: A within-subject test of information acquisition using strategic and financial cues. Academy of Management Journal, 37(4), 1017-1033.

Silvia, P. J. (2009). Looking past pleasure: Anger confusion disgust pride surprise and other unusual aesthetic emotions. Psychology of Aesthetics, Creativity, and the Arts, 3, 48-51. Retrieved December 1, 2018, from: http://psycnet.apa.org/fulltext/2009-01867-011.html

Winburg, S. S. (1991). Historical problem solving. A study of the cognitive processes used in the evaluation of documentary and pictorial evidence. Journal of educational psychology, 83(1), 73,87. 